\title{
REFLECTIONS ON \\ GENDER DISPARITY \\ IN STEM \\ HIGHER EDUCATION PROGRAMS: \\ PERSPECTIVES AND STRATEGIES
}

\section{Enyonam Brigitte Norgbey}

STEM is broadly perceived as a vital driver of sustainable development worldwide. However, women remain underrepresented in STEM fields despite decades of effort to bridge the gender gap. The purpose of this article is to understand the underlying factors that contribute to gender disparity in STEM and suggest effective interventions. Specifically, I seek to address the following questions: What factors contribute to gender disparity in graduate STEM program? What strategies can be adopted to address the issue?

This paper examines fifty articles published from 2006-2016 that had women or gender and/or science as a central part of their studies to analyze institutional and socio-cultural perspectives used to explain the situation and identify strategies that have been used to overcome the problem. Findings suggest that the factors that contribute to women underrepresentation in STEM are complex and numerous, calling for multi-faceted strategies to move the field forward.

Science, technology, engineering, and mathematics (STEM) are central to development agendas globally (Cheryan, Plaut, Davies, \& Steele 2009). Thus, STEM literacy is essential for economic development and global competitiveness as demonstrated by the widening gap of the development divide between north and south (Singh, 2011). However, women continue to be underrepresented in STEM fields, particularly at the graduate level (Rosenthal, London, Levy, \& Lobel, 2011; Boateng, 2015). This is unfortunate because women's untapped human capital can enhance the STEM workforce, given that women represent half of the world's population and more than $50 \%$ of its college-bound population (Dasgupta \& Stout, 2014). In fact, in 2009, American women received $37.7 \%$ of the chemistry PhDs, $20.3 \%$ 
of the physics PhDs, and $21.3 \%$ of the engineering PhDs awarded by colleges and universities (Else-Quest, Hyde, \& Linn, 2010).

Even though there has been steady growth in admissions in higher education (HE) over the last two decades, gender equity challenges in sub-Saharan Africa have been unprecedented (Mkude, 2011, Chikunda, 2010). Women who manage to make it into university tend to specialize in social science and humanities programs; there is limited enrollment in STEM programs (Morley, 2010; Acheampong, 2014). For example, the Ghana 2010 women undergraduate enrollment rate in Arts \& Humanities was $78 \%$ compared to $22 \%$ in STEM (Atuahene \& Owusu-Ansah, 2013).

Critics argue that gender stereotypes, lack of skilled, trained teachers, especially female teachers to act as role models, and the inability to implement gender policies contribute to the gender disparity (Mansfield, Welton, \& Grogan, 2014; Parson, 2016). Proponents of gender equality in HE contend that inequalities in HE institutions are structural, and require a closer look at gendered experiences and power relations within the institutions (Monroe \& Chiu, 2010; LaCosse, Sekaquaptewa, \& Bennett, 2016). Many scholars have used a multidisciplinary approach to explain the issue of gender disparity in STEM programs. This paper examines fifty published gender-related articles from 2006-2016 and analyzes the socio-cultural and institutional conditions used to explain the phenomenon. Further, this paper suggests strategies to overcome gender disparity in sub-Saharan Africa. The following key word phrases were used to locate articles online: "women in science" and "gender disparity in HE."

This paper addresses the following questions:

1. What institutional and socio-cultural perspectives have been used to explain the phenomenon?

2. What strategies can be adopted to address the issue, particularly in subSaharan Africa?

\section{Multidisciplinary perspectives}

STEM disciplines have been male dominated since their institutionalization as fields of study two centuries ago (Gilbert, 2009). Further, social and cultural practices, images, and identities of STEM are related to specific aspects of masculinity ${ }^{1}$, thus contributing to the proliferation of gender segregation in the fields (Gilbert, 2009; Holth \& Mellström, 2011).

\footnotetext{
${ }^{1}$ Masculinity relates to a society in which psychological gender roles are plainly clear. Men are supposed to be authoritative, strong, while women are supposed to be humble and caring (Hofstede, Hofstede, \& Minkov, 2010).
} 


\section{Institutional perspectives}

Stout, Dasgupta, Hunsinger, and McManus (2011) posit that institutional culture impedes women's pursuit of STEM programs. They argue that gender stereotypes and academic cultures influence women's achievements in STEM. Female students often view STEM education as a hostile environment that starts in secondary school and continues throughout $\mathrm{HE}$, whereas male students report being more comfortable and more active in STEM learning environments and thus receive more attention from teachers (Stoilescu \& McDougall, 2011).

STEM teaching methods foster a competitive learning environment that is not favorable to girls (Samson, 2014, \& Schulze \& van Heerden 2015). Studies show that women perform better in a cooperative learning environment (Leaper, 2015; LaCosse, Sekaquaptewa, \& Bennett, 2016). Practices that privilege competitive learning environments in STEM education exacerbate the ethical and social problems that challenge female students in STEM-related programs. This suggests a lack of efficiency in tackling the issue of gender disparity in STEM classes (Abbiss, 2008; Stoilescu \& Egodawatte, 2010).

The inadequacy of $\mathrm{HE}$ institutions in addressing the underrepresentation of women in STEM programs is reflected in a study undertaken by Ulriksen, Madsen, and Henriette (2010) that looks at STEM culture. They regard STEM culture as authoritative, competitive, impartial, and male dominated, and argue that STEM culture-as shown in the attitudes and practices of STEM teaching staff-contribute more to STEM attrition than individual student deficiencies. Further, they argue that STEM curricula and teaching practices that are often less contextual, less cooperative, and less student-centered contribute to student difficulties. In addition, they argue that the lack of female mentors in STEM disciplines also contribute to the underrepresentation of women in STEM programs (Rosenthal et al., 2013).

\section{Socio-cultural perspectives}

The home environment is also a contributing factor to gender disparity in the STEM fields. Parents' views influence gender differences in STEM disciplines. Eccles' (2015) study indicates that "parents' perceptions of their children's academic abilities predict the children's own confidence in their academic abilities" (p. 120). The study also showed that parents' beliefs about their children's capabilities differ according to the sex of their children. The culturally shared gender stereotype that males are naturally more talented in math than females causes parents to overstate their sons' math abilities and underestimate their daughters' math aptitudes (Eccles, 2015).

Archer et al. (2013) note that parents as important role models influence the career choices of their children through advice, and encouragement, financial and emotional support, among other things. Mothers in particular play an important role in the career choice of their daughters. If mothers value social sciences and humanities 
such as arts, linguistics, education, both they and their daughters are likely to develop a keen interest in professional careers traditionally assigned to women such as teaching, social work, nursing, etc. (Mujawamariya, 2013).

In addition to institutional and parental factors, society also contributes to gender disparity in STEM programs in sub-Saharan Africa (Sinnes \& Loken, 2014). Lynch and Nowosenetz (2009) studied undergraduate STEM students and examined their awareness of gender inequality issues in STEM programs. Their findings suggest that students (boys and girls) rely on traditional gender roles and that they build gender around cultural beliefs and values-girls are supposed to be the caregivers and do not belong in STEM fields - that they perceive provide social stability. Such beliefs and values also have an impact on teachers' perception, reasoning, and practices in STEM programs. Chikunda's (2014) study provides insights into how culture and patriarchy negatively affect STEM teaching styles and curricula, thereby reinforcing gender disparity in HE and in STEM programs.

Patriarchy is a hierarchical structure that cuts across political, economic, social, religious, cultural, industrial, educational, and financial domains. Patriarchies assign unjustifiable numbers of decision-making positions in society to be headed by men and justifies males' domination over females. Regardless of the dominant patriarchal historical form - such as feudal, ${ }^{2}$ capitalist, socialist, and economic discriminationadopted by society, all forms of patriarchy operate simultaneously (Evans, 2015). Gender roles are socially and culturally constructed for men and women, but in patriarchal societies, women are given the caring role and men are given the breadwinner's role and work outside of the house (Makama, 2013; Shin et al., 2015). Thus, as an institutionally-established discourse, patriarchy is an essential tool in analyzing STEM-related gender disparity, and power relations (Sinnes \& Loken, 2014; Menon, 2015).

While many factors contribute to gender disparity in STEM, the major factors include a lack of awareness of the role gender, institutional cultures, and societal beliefs play in shaping girls' and women's conception of themselves in the STEM disciplines.

\section{Strategies to Reduce Gender Disparity in STEM Programs}

Strategies to address gender disparity in STEM include: 1) advocacy to raise awareness; 2) gender affirmative action; 3) gender mainstreaming; and 4) capabilitiesbased policies and practices. Different actors such as policy makers, heads of

\footnotetext{
${ }^{2}$ Patriarchal feudalism is described as a set of implied exchanges in which the subordinated groups (such as serfs, women, or children) obtained protection and security in return for working long hours in the service of their masters. http://blog.oup.com/2011/02/patriarchal-feudalism/\#sthash.8KKSqUQB.dpuf
} 
departments, faculty members, students, parents, and the entire community need to work together to address the issue of gender disparity in STEM.

Advocacy to raise awareness about gender disparity issues in STEM

Awareness campaigns that contribute to a collective consciousness of gender equality start the process of the community and stakeholder buy-in necessary for policy development debates for subsequent transformation. Such campaigns promote gender equality as social justice that provides fair and equal opportunities for every student, including the participation of women and girls in all educational, economic, social, and political structures (DeJaeghere \& Wiger, 2013). Dissemination of research findings on gender and STEM gender disparity help promote advocacy for increased participation of girls and women in STEM while raising awareness about the gender inequity issues.

The creation of advocacy groups also helps to raise consciousness about gender issues in STEM. For example, "L'AFESTIM (Association de la francophonie à propos des femmes en sciences, technologies, ingénierie et mathématiques), International Network of Women Engineers and Scientists, etc." (Deschênes, 2008, p. 147) all advocate for women's and girls' issues. Similarly, Machira (2013) calls for development practitioners such as non-governmental organizations (NGOs), and advocacy groups like the Forum for African Women Educationalists (FAWE) ${ }^{3}$, the African Women in Science and Engineering (AWSE) ${ }^{4}$, etc. to promote, encourage, and support girls and women to pursue education to the highest level especially in STEM.

\section{Gender affirmative action approach}

While it is important to sensitize the populations to gender disparity issues in STEM, concrete gender affirmative action in STEM program recruitment and retention is imperative in creating a critical mass of women in STEM to serve as role models and mentors for young girls and women aspiring to pursue STEM-related careers.

Affirmative action has been used successfully to attain gender parity 5 in many parts of the world, including sub-Saharan Africa (Hlalele \& Alexander, 2012; Chauraya, 2014).

\section{Gender mainstreaming}

Gender mainstreaming is a process that promotes gender equality by profiling gender perspectives at all stages of the development and implementation of policies,

\footnotetext{
${ }^{3}$ FAWE is a pan-African non-governmental organization to promote girls' and women's education in subSaharan Africa by making sure they have access to schools and are able to complete their studies and fulfill their educational goals (www.fawe.org).

${ }^{4}$ AWSE is an organization that serves women scientists and engineers, through chapters in various African countries. It is an organization that seeks to increase the numbers of competent women scientists and engineers within Africa. (www.awse.org).

${ }^{5}$ Gender parity relates to the equal representation of males and females in a specific context.
} 
plans, programs, projects as well as STEM curricula and teaching practices. Gender mainstreaming brings to the fore discourses about gender issues and establishes new directions on how to move the gender inequality debates forward (Unterhalter, 2007). It entails discussions of all gendered assumptions, processes, and perceptible results (Karlsson, 2010) to improve key policies. Gender mainstreaming promotes gender equality within institutions if implemented effectively, and therefore enhances social justice $^{6}$ (Unterhalter \& North, 2010).

\section{Capabilities-based approach}

While effective gender mainstreaming leads to gender equality, the inclusion of capabilities-based policy and practices in teaching/learning has the potential to strengthen the gender equality process. In recent years, a global focus on issues of social justice and gender equality has increased access for women to HE and STEM. Even though the concept of social justice is a source of tension in $\mathrm{HE}$, particularly in the STEM disciplines (Walker, 2015), and global economic growth and human capital has led to gender equity ${ }^{7}$ problems in many countries around the world and particularly in sub-Saharan Africa (Nussbaum, 2011), the capabilities-based approach facilitates building "graduates' capabilities and functioning" (Walker, 2015, p. 417) that are in line with the skills the students need and value. In fact, the training process focuses on the well-being of the students, what they can do, and their quality of life (Loots \& Walker, 2016).

\section{Conclusion}

Factors that contribute to the underrepresentation of women in STEM are complex and varied. In this paper, I discussed institutional and socio-cultural perspectives to gender disparity in STEM together with specific strategies that could be adopted to reduce it. Even though culture and patriarchy are also relevant to other parts of the world, they are mostly pertinent in the context of sub-Saharan Africa. The global community and African universities have much to gain by striving to reduce gender disparity in STEM to effectively contribute to global development.

\section{References}

\footnotetext{
${ }^{6}$ Social justice relates to human rights and is the notion of how "the burdens and benefits of society should be fairly and equitably distributed" (Rogers \& Kelly, 2011, p. 398). It involves "equal justice, not just in the courts, but in all aspects of society" (Hlalele \& Alexander, 2012, p. 488).

${ }^{7}$ Gender equity thus relates to the fair distribution of responsibilities, resources, and power between men and women. Meanwhile, men and women have disparate needs, responsibilities, and access to resources. Therefore, these differences have to be identified and addressed efficiently, especially if these differences lead to unfair treatment of girls and women (Baily \& Holmarsdottir, 2015).
} 
Abbiss, J. (2008). Rethinking the 'problem' of gender and IT schooling: Discourses in literature. Gender and Education, 20(2), 153-165.

Acheampong, A. B. (2014). Inequality of Gender Participation of Females in STEM Disciplines in Higher Education: A case study of KNUST: Ghana. Retrieved from http://hdl.handle.net/10852/43101, February 2, 2017.

Archer, L., DeWitt, J., Osborne, J., Dillon, J., Willis, B., \& Wong, B. (2013). Not girly, not sexy, not glamorous: Primary girls' and parents' constructions of science aspiration. Pedagogy, Culture \& Society, 21(1), 171-194.

Atuahene, F., \& Owusu-Ansah, A. (2013). A descriptive assessment of higher education access, participation, equity, and disparity in Ghana (pp. 1-16). Sage Open. doi: 10.1177/2158244013497725.

Baily, S., \& Holmarsdottir, H. B. (2015). The quality of equity? Reframing gender, development and education in the post-2020 landscape. Gender and Education, 27(7), 828-845.

Boateng, F. K. (2015). Dealing with the ball and chain: A grounded theory study of the experiences of women in STEM domains in Ghana (Ph.D.). University of Florida, United States -- Florida. Retrieved from: http://search.proquest.com.proxy.bib.uottawa.ca/pqdtglobal/docview/1786686317 /A9CC2C72A7084503PQ/1, February 1, 2017.

Chauraya, E. (2014). Access or inclusion? Conceptualisation and operalisation of gender equality in Zimbabwean state universities. Perspectives in Education, 32(4), 4-19.

Cheryan, S., C., Plaut, V. C., Paul G., Davies, P. G., \& Steele, C.M. (2009). Ambient belonging: How stereotypical cues impact gender participation in computer science. Journal of Personality and Social Psychology, 97(6), 1045-1060.

Chikunda, C. (2010). Assessing the level of gender awareness of science teachers: The case of Zimbabwe's two education districts. African Journal of Research in Mathematics, Science and Technology Education, 14(3), 110-120.

Chikunda, C. (2014). Identifying tensions around gender-responsive curriculum practices in science teacher education in Zimbabwe: An activity theory analysis. African Journal of Research in Mathematics, Science and Technology Education, 18(3), 264-275.

Dasgupta, N., \& Stout, J. G. (2014). Girls and women in science, technology, engineering, and mathematics STEMing the tide and broadening participation in STEM careers. Policy Insights from the Behavioral and Brain Sciences, 1(1), 21-29.

DeJaeghere, J., \& Wiger, N. P. (2013). Gender discourses in an NGO education project: Openings for transformation toward gender equality in Bangladesh. International Journal of Educational Development, 33, 557-565.

Deschênes, C. (2008). Dimension internationale du leadership. Dans L., Lafortune, C., Deschênes, M. C., Williamson, et P., Provencier, (Collectif arbitré, sous la dir.). 
Le leadership des femmes en STIM: Sciences, technologies, ingénierie et mathématiques, (pp. 143-159). Québec : PUQ, Collection Éducation/Intervention.

Eccles, J. S. (2015). Gendered socialization of STEM interests in the family. International Journal of Gender Science and Technology, 7(2), 116-132.

Else-Quest, M. N., Hyde, J. S., \& Linn, M. C. (2010). Cross-national patterns of gender differences in mathematics: A meta-analysis. Psychological Bulletin, 136(1), 103127.

Evans, E. (2015). What makes a (third) wave? International Feminist Journal of Politics, 1-20.

Gilbert, A. F. (2009). Disciplinary cultures in mechanical engineering and materials science: Gendered/gendering practices. Equal Opportunities International, 28(1), 24-35.

Hlalele, D., \& Alexander, G. (2012). University access, inclusion and social justice. South African Journal of Higher Education, 26(3), 487-502.

Hofstede, G., Hofstede, G. J., \& Minkov, M. (2010). Cultures and organizations. McGraw-Hill.

Holth, L., \& Mellström, U. (2011). Revisiting engineering, masculinity and technology studies: Old structures with new openings. International Journal of Gender Science and Technology, 3(2), 313-329.

Karlsson, J. (2010). Gender mainstreaming in a South African provincial education department: A transformative shift or technical fix for oppressive gender relations? Compare: A Journal of Comparative and International Education 40(4), 497-514.

LaCosse, J., Sekaquaptewa, D., \& Bennett, J. (2016). STEM stereotypic attribution bias among women in an unwelcoming science setting. Psychology of Women Quarterly, 1-20.

Leaper, C. (2015). Do I Belong? Gender, peer groups, and STEM achievement. International Journal of Gender, Science and Technology, 7(2), 166-179.

Loots, S., \& Walker, M. (2016). A capabilities-based gender equality policy for higher education: Conceptual and methodological considerations. Journal of Human Development and Capabilities, 7(2), 260-277.

Lynch, I., \& Nowosenetz, T. (2009). An exploratory study of students' constructions of gender in science, engineering and technology. Gender and Education, 21(5), 567-581.

Machira, M. A. (2013). The experience of patriarchy by Kenyan women in the pursuit of higher education. ProQuest LLC. 789 East Eisenhower Parkway; Retrieved from http://search.proquest.com.proxy.bib.uottawa.ca/eric/docview/1697502107/E44C1 7039D53413BPQ/11. 
Makama, G. A. (2013). Patriarchy and gender inequality in Nigeria: The way forward. European Scientific Journal, 9(17), 115-144.

Mansfield, K.C., Welton, A.D., \& Grogan, M. (2010) "Truth or consequences": A feminist critical policy analysis of the STEM crisis. International Journal of Qualitative Studies in Education, 27(9), 1155-1182.

Menon, N. (2015). Fighting patriarchy and capitalism. Journal of Contemporary African Studies, 3(1), 3-11.

Mkude, D. (2011). Higher education as an instrument of social integration in Tanzania: Challenges and prospects. Research in Comparative and International Education, 6(4), 366-373.

Monroe, K., R., \& Chiu, I.W. (2010). Gender Equality in the Academy: The pipeline problem. The Profession, 303-308.

Morley, L. (2010). Gender mainstreaming: Myths and measurement in higher education in Ghana and Tanzania. Compare, 40(4), 533-550.

Mujawamariya, D. (2013). Enseigner les sciences en milieu francophone minoritaire : perceptions d'enseignantes et d'enseignants francophones de l'Ontario. Dans S. Houde et J-C. Kalubi (dirs.). Intégrer des matières ou développer des apprentissages? Approches plurielles en milieu scolaire, (pp. 51-62). Québec: Les presses interuniversitaires.

Nussbaum, M. C. (2011). Capabilities. The human development approach. Cambridge, Massachusetts: Harvard University Press.

Parson, L. (2016). Are STEM syllabi gendered? A feminist critical discourse analysis. The Qualitative Report, 21(1), 102-116.

Rogers, J., \& Kelly, U. A. (2011). Feminist intersectionality: Bringing social justice to health disparities research. Nursing Ethics, 18(3), 397-407.

Rosenthal, L., London, B., Levy, S.R., \& Lobel, M. (2011). The roles of perceived identity compatibility and social support for women in a single-sex STEM program at a co-educational university. Sex Roles, 65, 725-736.

Rosenthal, L., Levy, S. R., London, B., Lobel, M., \& Bazile, C. (2013). In pursuit of the MD: The impact of role models, identity compatibility, and belonging among undergraduate women. Sex Roles, 68, 464-473.

Samson, G. (2014). Les filles dans le contexte de la technologie et de l'ingénierie : Pistes d'intervention et recommandations, Dans A. Roy, D. Mujawamariya et L., Lafortune, Des actions pédagogiques pour guider les filles et les femmes en STIM: Sciences, technos, ingénierie et maths, (pp. 55-67). Québec : PUQ.

Schulze, S., \& van Heerden, M. (2015). Learning environments matter: Identifying on the motivation to learn science. South African Journal of Education, 35(2), 1-9. 
Shin, J. et al. (2015). Home and motivational factors related to science-career pursuit: Gender differences and gender similarities. International Journal of Science Education, 37(9), 1478-1503.

Singh, M. (2011). Equity and quality in the revitalisation of African higher education: Trends and challenges. Research in Comparative and International Education, 6(4), 348-365.

Sinnes, A.T., \& Loken, M. (2014). Gendered education in a gendered world: Looking beyond cosmetic solutions to the gender gap in science. Cultural Studies of Science Education, 9(2), 343-364.

Stoilescu, D., \& Egodawatte, G. (2010). Gender differences in the use of computers, programming, and peer interactions in computer science classrooms. Computer Science Education, 20(4), 283-300.

Stoilescu, D., \& McDougall, D. (2011), Gender digital divide and challenges in undergraduate computer science programs. Canadian Journal of Education 34(1), 308-333.

Stout, J. G., Dasgupta, N., Hunsinger, M., \& McManus, M. A. (2011). STEMing the tide: Using in-group experts to inoculate women's self-concept in science, technology, engineering, and mathematics (STEM). Journal of Personality and Social Psychology, 100(2), 255-270.

Ulriksen, L., Madsen, L.M., \& Holmegaard, H.T. (2010). What do we know about explanations for drop out/opt out among young people from STM higher education programmes? Studies in Science Education, 46(2), 209-244.

Unterhalter, E. 2007. Gender, schooling and global social justice. Abingdon, UK: Routledge.

Unterhalter, E., \& North, A. (2010). Assessing gender mainstreaming in the education sector: depoliticised technique or a step towards women's rights and gender equality? Compare: A Journal of Comparative and International Education, 40(4), 389-404.

Walker, M. (2015). Imagining STEM higher education futures: Advancing human well-being. High Education, 70, 417-425. 